\title{
iFR-guided assessment of angiographically intermediate coronary artery stenoses in different clinical settings - a case series
}

\section{Željko Baričević”, Kristina Marić Bešić, Maja Strozzi, Joško Bulum}

University of Zagreb School of Medicine, University Hospital Centre Zagreb, Zagreb,

Croatia

\begin{abstract}
KEYWORDS: instantaneous wave-free ratio, percutaneous coronary intervention, multivessel coronary disease.

CITATION: Cardiol Croat. 2018;13(1-2):53-54. | https://doi.org/10.15836/ccar2018.53

*ADDRESS FOR CORRESPONDENCE: Željko Baričević, Klinički bolnički centar Zagreb, Kišpatićeva 12, HR-10000 Zagreb, Croatia. / Phone: +385-1-2367-508 / E-mail: zbaricev@gmail.com

ORCID:Željko Baričević, https://orcid.org/0000-0002-5420-2324 • Kristina Marić Bešić, https://orcid.org/0000-0002-4004-7271 Maja Strozzi, https://orcid.org/0000-0003-4596-8261 • Joško Bulum, https://orcid.org/0000-0002-1482-6503
\end{abstract}

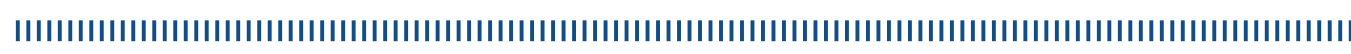

Background: Making final decisions to perform percutaneous coronary intervention (PCI) based on angiographic results, without taking into consideration objective physiologic parameters that are not subject to misinterpretation, is a major issue in many cardiac catheterization laboratories. Despite numerous studies indicating their weakness, far too many operators still rely on visual angiography estimates or quantitative coronary angiography (QCA) for treatment guidance. This may be especially problematic in technically demanding lesions, bifurcation or multivessel disease, in which case a misinterpreted stenosis severity may lead to over- or undertreatment and possibly worse outcomes. Game-changing technology of instantaneous wavefree ratio (iFR) (Figure 1), which is performed with high fidelity pressure wire that is passed distal to the lesion to determine whether a stenosis is causing a limitation of flow with subsequent ischemia, is very feasible in daily clinical practice ${ }^{1}$. In terms of cost-effectiveness with the adoption of iFR, although there is still a large reimbursement issue to be accounted for in Croatia, there are also some obvious benefits rising from elimination of unnecessary treatments and reduction in hospital readmissions. To support the concept, we are presenting a series of clinical decision-making cases from our institution, using iFR-guided assessment of angiographically intermediate coronary artery stenoses in different clinical settings.

Case 1 - Angiographically non-significant right coronary artery (RCA) lesion: 77-year-old female with the history of arterial hypertension and dyspnea on exertion was referred for coronary angiography, following inconclusive treadmill exercise stress test. A long proximal to mid-segment RCA stenosis of borderline angiographic appearance was noted; however, iFR of 0.71 demonstrated true lesion severity. PCI RCA with a single drug-eluting stent (DES) implantation and high-pressure balloon postdilatation was performed.

\section{RECEIVED:}

February 4, 2018

ACCEPTED:

February 10, 2018

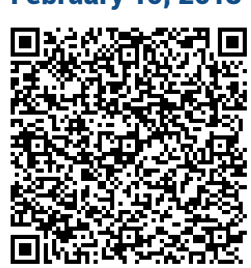

Case 2 - Multivessel disease: 59-year-old male smoker with newly diagnosed arterial hypertension, diabetes and old anteroseptal myocardial infarction was admitted due to unstable angina. Coronary angiography showed old ostial left anterior descending artery (LAD) occlusion, culprit subocclusive stenosis of the proximal circumflex artery (Cx) with the plaque extending from the left main coronary artery (LMCA) and severely ectatic RCA with multiple aneurysms, angiographically intermediate stenosis of the mid-segment and calcified stenosis of the posterior descending (PD) branch. PCI LMCA/CX was performed with 2 DES implanted, followed by iFR of the RCA one month later, in a staged manner PD stenosis was found positive (0.85) and treated with DES implantation, but the prognostically challenging mid-RCA stenosis was iFR negative (0.94) and subsequently left untreated.

Case 3 - Diffuse LAD disease: 60-year-old male patient with previous PCI RCA for myocardial infarction was referred for second-look coronary angiography due to residual diffuse LAD disease beginning at the ostium level and angiographically significant Cx stenosis (QCA 75\%). By means of iFR, Cx lesion was found negative $(0,91)$ and the LAD was positive $(0.85)$, which was confirmed by fractional flow reserve finding of 0.75 . Using iFR pullback method (Figure 2) a jump was demonstrated at the level of LAD/2nd diagonal (D) bifurcation (Medina classification $0,1,0$ ) that led to PCI with 1 drug-coated balloon applied to treat the lesion. Due to localized dissection, an additional DES was implanted proximally Myocardial SPECT was performed 4 months later showing no inducible ischaemia.

Case 4 - Unstable angina with bifurcation LAD/D1 stenosis: 57 year-old woman was hospitalized due to single episode of angina at rest, with ischaemic ECG changes in leads I and aVL. Coronary angiography showed bifurcation lesion involving subocclusion of the small D1 as a culprit lesion and angio- 


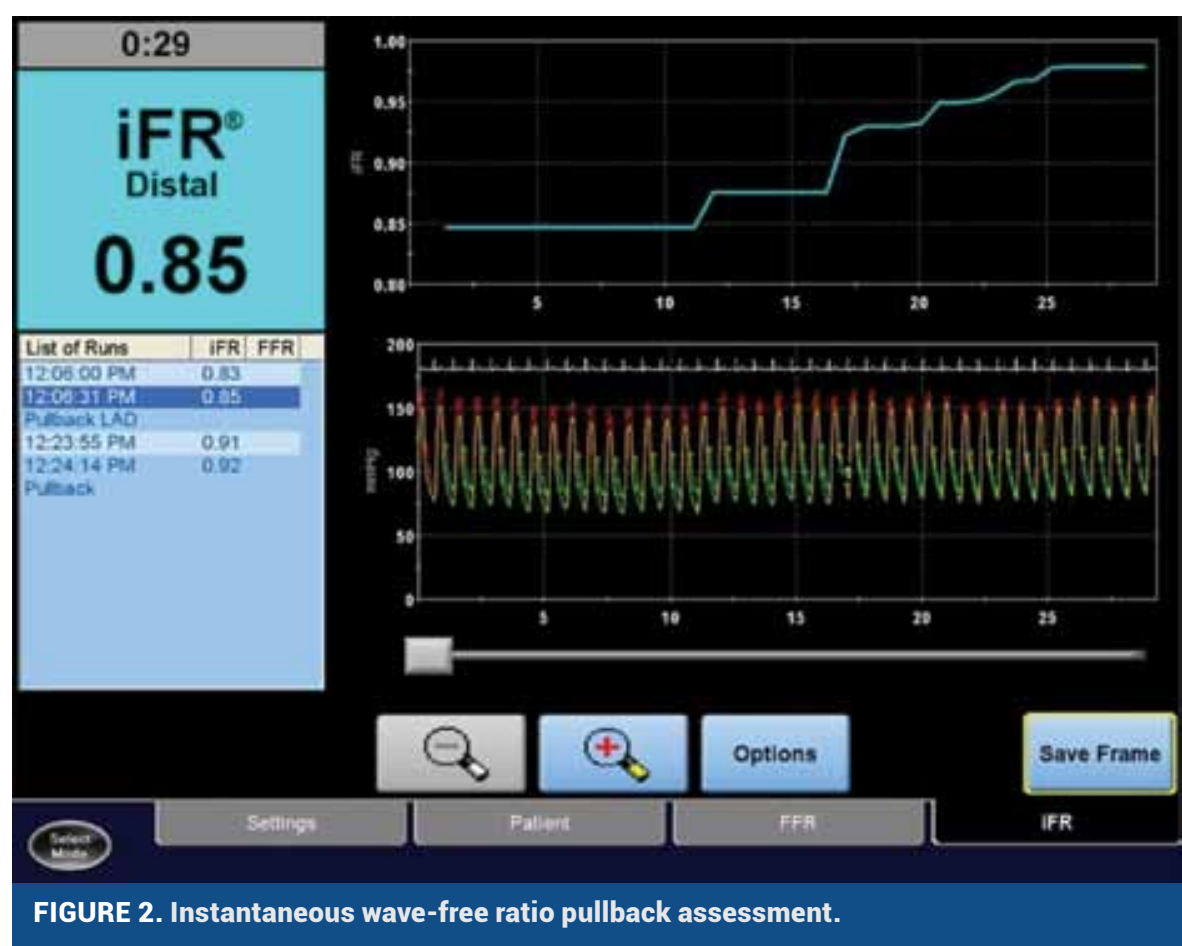

graphically intermediate LAD stenosis (Medina classification 1,0,1). The patient had been free of chest pain from the time of the admission. iFR was done revealing that the LAD stenosis was not flow-limiting (0.98) and the patient was discharged with optimal medical therapy only.

Conclusion: Physiological assessment of angiographically intermediate coronary artery lesions using iFR is feasible and should be performed on a regular basis to improve patient treatment and outcomes. 